\title{
IDENTIFICATION OF YEASTS ISOLATED FROM POULTRY MEAT*
}

\author{
T. DEÁK** \\ Department of Microbiology, Szent István University, \\ Somlói út 14-16, H-1118 Budapest, Hungary
}

(Received: August 31, 2000; accepted: October 5, 2000)

\begin{abstract}
In an assessment of the potential role of yeasts in the spoilage of poultry meat, the population and species diversity of yeasts were determined on 50 commercial raw and processed chicken and turkey product samples. Initial populations $\left(\log _{10} \mathrm{cfu} / \mathrm{g}\right)$ ranged from less than 0.1 to 2.9 , and increased by the expiration date to 0.4 to 5.1, respectively. 145 of 152 isolates were identified as belonging to 12 species. Yarrowia lipolytica and Candida zeylanoides were predominant, accounting for $39 \%$ and $26 \%$ of the isolates, respectively. Six different species of basidiomycetous yeasts were determined representing $24 \%$ of the isolates. The ability of the predominant yeast species to grow at refrigeration temperatures and their proteolytic and lipolytic activies suggest that yeasts may play a more significant role than previously recognised in the spoilage of poultry products.
\end{abstract}

Keywords: Yeasts - identification - spoilage - poultry - chicken - turkey

\section{INTRODUCTION}

The spoilage of poultry meat is largely attributed to the activity of bacteria [7], but yeasts are also regularly present in the microbiota. Yeast population in the range of $10^{2}$ to $10^{4} \mathrm{cfu} / \mathrm{g}$ have been reported on fresh chicken carcasses, levels that may increase to over $10^{5} \mathrm{cfu} / \mathrm{g}$ upon refrigerated storage $[4,5]$. Only a few surveys have been performed to identify yeast species on poultry meat. Diriye et al. [3] observed that Candida zeylanoides and Yarrowia lipolytica were the major yeast species isolated from frozen chicken. Viljoen et al. [8] described 20 yeast species representing 7 genera from fresh and spoiled poultry. In the study by Ismail et al. [6], the initial populations of yeasts on fresh and processed poultry products were observed to range from less than $0.1 \log _{10} \mathrm{cfu} / \mathrm{g}$ to $2.9 \log _{10} \mathrm{cfu} / \mathrm{g}$, levels that increased to as high as 5.1 $\log _{10} \mathrm{cfu} / \mathrm{g}$ when samples were stored at $5{ }^{\circ} \mathrm{C}$ up to their expiration date. A great number of yeast isolates were collected in that study, many of which exhibited strong proteolytic and lipolytic activities.

\footnotetext{
*Dedicated to Professor Lajos Ferenczy on the occasion of his 70th birthday.

**Corresponding author; e-mail: tdeak@omega.kee.hu
} 
Since yeasts may play a substantial role in the spoilage of poultry meat, a further study was undertaken to identify yeasts isolated from poultry samples. The work presented here describes the identification by means of conventional physiological tests; the molecular characterisation of representative isolates has been published separately [2].

\section{MATERIALS AND METHODS}

\section{Poultry products}

Fifty commercial samples representing 15 fresh (whole or ground, and parts such as breast, leg, wing, neck or liver) or processed (marinated, smoked or roasted) chicken and turkey products were subjected to microbiological analysis.

\section{Enumeration and isolation}

Twenty g of each sample was comminuted in a stomacher and $0.1 \mathrm{ml}$ decimally diluted aliquots were surface plated on dichloran rose bengal chloramphenicol (DRBC) agar or on tryptone glucose yeast extract agar supplemented with chloramphenicol (TGYC). Plates were incubated at $25^{\circ} \mathrm{C}$ for $3-5$ days, and dilutions yielding $10-100$ colonies were counted. Three to five representative colonies were chosen from each sample, and isolates after repeated streaking were held at $5{ }^{\circ} \mathrm{C}$ until identified.

\section{Identification}

The simplified identification method (SIM) confined to the most frequent foodborne yeasts was used [1]. The procedure was carried out in two phases. First, a preliminary grouping of the isolates was made on the basis of the results of six tests (urease reaction, growth in the presence of $0.1 \%$ cycloheximide, and the assimilation of nitrate, erythritol, mannitol and cellobiose). In addition, all isolates were examined microscopically and for colony morphology. In the second phase, additional tests selected according to each group were performed to achieve and confirm identification. These tests included growth at $37^{\circ} \mathrm{C}$, the formation of starch-like compounds, the assimilation of L-arabinose, cadaverine, ethylamine, galactose, glucuronate, inositol, 2-ketogluconate, lysine, maltose, melibiose, methyl- $\alpha$-glucoside, raffinose, and fermentation of glucose.

All physiological tests were performed according to the conventional procedures described for SIM [1]. 


\section{RESULTS AND DISCUSSION}

\section{Populations of yeasts on poultry meat}

With the exception of 4 roasted turkey samples, yeasts were found in all poultry products (Table 1). Their mean population, as counted on DRBC agar, in $\log _{10} \mathrm{cfu} / \mathrm{g}$, ranged from 0.6 to 4.1 initially and from 1.6 to 5.1 at the expiration date, whereas on TGYC agar somewhat lower counts were obtained, ranging less than 0.1 to 2.9 initially and 0.4 to 5.1 at the expiration date. These populations are in agreement with yeast counts observed by others in previous investigations. The differences in the populations of the yeasts between raw and processed products were not surprising; in particular low or undetectable counts were expected in heat-treated (roasted) products. The yeast populations also differed on the various poultry parts, as noted by Gallo et al. [4].

Table 1

Populations of yeasts on chicken and turkey products

\begin{tabular}{|c|c|c|c|c|c|}
\hline \multirow{3}{*}{\multicolumn{2}{|c|}{ Product }} & \multicolumn{4}{|c|}{ Mean populations $\left(\log _{10} \mathrm{cfu} / \mathrm{g}\right)^{\#}$ on } \\
\hline & & \multicolumn{2}{|c|}{ DRBC medium } & \multicolumn{2}{|c|}{ TGYC medium } \\
\hline & & initially & at expiration & initially & at expiration \\
\hline \multirow[t]{8}{*}{ Chiken } & breast & 3.0 & 3.7 & 2.9 & 3.4 \\
\hline & leg & 1.8 & 3.2 & 1.6 & 3.2 \\
\hline & wing & 2.6 & 3.7 & 2.7 & 3.1 \\
\hline & liver & 2.0 & 3.9 & 1.9 & 4.5 \\
\hline & whole & 2.1 & 5.5 & 2.0 & 3.5 \\
\hline & ground & 2.2 & 5.1 & 2.0 & 3.5 \\
\hline & marinated & 2.4 & 2.6 & 2.0 & 3.0 \\
\hline & roasted & 0.7 & 1.6 & 1.1 & 1.8 \\
\hline \multirow[t]{5}{*}{ Turkey } & leg & 2.9 & 4.0 & 2.4 & 4.7 \\
\hline & neck & 4.1 & 4.8 & 2.3 & 4.1 \\
\hline & ground & 2.0 & 4.2 & 1.5 & 3.5 \\
\hline & smoked & 0.6 & 3.4 & 1.8 & 3.0 \\
\hline & roasted & $0.0^{*}$ & 0.0 & 0.0 & 0.4 \\
\hline
\end{tabular}

\#Data are means of duplicate analyses of 2 to 7 samples.

*Less than $0.1 \log _{10} \mathrm{cfu} / \mathrm{g}$, detection limit.

\section{Identification of isolates}

In all, 145 of 152 strains isolated from poultry samples were identified. Table 2 shows the yeast species found on the various samples, and Table 3 details their salient characteristics. 


\begin{tabular}{|c|c|c|c|c|c|c|c|c|}
\hline \multirow{4}{*}{ Yeasts } & on of ye & ecies a & $\begin{array}{r}\text { Table } \\
\text { ates fr }\end{array}$ & icken an & key parts an & ducts & & \\
\hline & \multirow{3}{*}{ Total } & \multirow{3}{*}{$\%$} & \multicolumn{6}{|c|}{ Number of isolates } \\
\hline & & & \multicolumn{3}{|c|}{ Chicken } & \multicolumn{3}{|c|}{ Turkey } \\
\hline & & & parts & ground & processed & parts & ground & processed \\
\hline Candida catenulata & 2 & 1.3 & 1 & & 1 & & & \\
\hline Candida parapsilosis & 5 & 3.3 & 3 & & 1 & & & 1 \\
\hline Candida zeylanoides & 40 & 26.3 & 11 & 2 & 13 & 3 & 5 & 6 \\
\hline Cryptococcus albidus & 2 & 1.3 & & 1 & 1 & & & \\
\hline Cryptococcus hungaricus & 1 & 0.6 & & & 1 & & & \\
\hline Cryptococcus humicolus & 2 & 1.3 & 1 & & 1 & & & \\
\hline Cryptococcus laurentii & 7 & 4.6 & & 3 & 4 & & & \\
\hline Cystofilobasidium informominiatum & 7 & 4.6 & 2 & 3 & & 2 & & \\
\hline Debaryomyces hansenii & 2 & 1.3 & & 2 & & & & \\
\hline Rhodotorula glutinis & 11 & 7.2 & 2 & 1 & 3 & 3 & 1 & 1 \\
\hline Rhodotorula mucilaginosa & 6 & 4.0 & 2 & 12 & 1 & 1 & 1 & \\
\hline Yarrowia lipolytica & 60 & 39.5 & 16 & 3 & 31 & 4 & 4 & 2 \\
\hline Not identified & 7 & 4.6 & 2 & & 3 & 1 & 1 & \\
\hline
\end{tabular}


Table 3

Salient characteristics of yeast species isolated from poultry products

\begin{tabular}{lccccccccc}
\hline \multicolumn{1}{c}{ Yeast } & Ure & $\mathrm{Cycl}$ & $\mathrm{NO}_{3}$ & Ert & $2 \mathrm{Kg}$ & $\mathrm{Glc}$ & Ferm & Pink & Hyph \\
\hline Candida catenulata & - & + & - & - & - & $\mathrm{nt}$ & + & - & - \\
Candida parapsilosis & - & - & - & - & - & $\mathrm{nt}$ & + & - & - \\
Candida zeylanoides & - & + & - & - & - & $\mathrm{nt}$ & - & - & - \\
Cryptococcus albidus & + & + & + & + & - & + & - & - & - \\
Cryptococcus humicolus & + & + & - & + & - & + & - & - & + \\
Cryptococcus hungaricus & + & - & - & - & - & + & - & + & - \\
Cystof. infirmoniniatum & + & - & + & - & - & + & - & + & + \\
Debaryomyces hansenii & - & $\mathrm{v}$ & + & - & - & $\mathrm{nt}$ & - & - & - \\
Rhodotorula glutinis & + & $\mathrm{v}$ & + & - & - & - & - & + & - \\
Rhodotorula mucilaginosa & + & $\mathrm{v}$ & - & - & - & - & - & + & - \\
Yarrowia lipolytica & - & + & - & + & - & $\mathrm{nt}$ & - & - & + \\
\hline
\end{tabular}

Abbreviations: Ure: urease reaction; Cycl: resistance to $0.1 \%$ cycloheximide; $\mathrm{NO}_{3}$ : assimilation of nitrate; Ert: assimilation of erythritol; $2 \mathrm{Kg}$ : assimilation of 2-ketogluconate; Glc: assimilation of glucuronate; Ferm: fermentation of glucose; Pink: colony color; Hyph: formation of true hyphae.

Reactions: +: positive; -: negative; v: variable; nt: not tested.

With the six first-stage tests of SIM, the isolates were divided into three groups. Group 1 consisted of 37 urease-positive isolates, Group 2 included 63 isolates, all of which assimilated erythritol, whereas Group 3 comprised the 52 erythritol-negative isolates.

In Group 1, 6 basidiomycetous species were distinguished according to colony colour, the assimilation of nitrate, erythritol, inositol, glucuronate, and melibiose, and the formation of starch-like compounds. One isolate exhibited similarities to Mrakia frigida in assimilating neither inositol nor glucuronate, though it did grow at $37^{\circ} \mathrm{C}$; it is listed among the unidentified isolates.

Most isolates in Group 2 were quite similar. They were all cycloheximide-resistant and formed true and/or pseudohyphae, and most of them also a pellicle in broth culture. They generally assimilated very few compounds and did not ferment glucose; they were identified with Yarrowia lipolytica. Two isolates which did not form hyphae but assimilated several substrates were assigned to Debaryomyces hansenii. One isolate that was not identified was similar to Y. lipolytica, but did not produce hyphae. A majority of the isolates in Group 3 were cycloheximide-resistant, not fermentative and assimilated a limited range of substrates. Their characters well fitted those of Candida zeylanoides. Only a few isolates differed from this species in their assimilation patterns and ability to ferment glucose. Two isolates were identified as C. catenulata and 5 as C. parapsilosis, but the identity of another 5 isolates could not be established with the tests performed. 


\section{Distribution of species}

Of the 152 isolates, 145 were identified as belonging to 12 species (Table 2). 116 isolates originated from 32 chicken samples, whereas 36 isolates were from 18 turkey samples. Y. lipolytica and C. zeylonoides were predominant, making up $39.5 \%$ and $26.3 \%$ of the isolates, respectively. Basidiomycetous species represented $24 \%$ of the isolates, and their percentage distribution was similar to that observed in earlier studies, but the occurrence of a large number of different basidiomycetous species on poultry meat was previously unknown. Viljoen et al. [8] reported that 35\% and $45 \%$ of yeasts isolated from fresh or spoiled chicken samples were C. zeylanoides. In that study, the other prevalent species were Debaryomyces hansenii (5-26.6\%) and $Y$. lipolytica (2.5-11.4\%). Diriye et al. [3] reported data similar to those in this study in that C. zeylanoides (58.3\%), Y. lipolytica (16.7\%) and Rhodotorula rubra $(16.7 \%)$ were the predominant yeasts isolated from frozen chicken.

The persistence of C. zeylanoides and Y. lipolytica in poultry meat can be attributed to their ability to grow at refrigeration temperatures, and to their proteolytic and lipolytic activities [6]. These lytic processes may provide readily available nutrients for bacterial growth, thereby indirectly enhancing the rate of spoilage. The results of this study indicate that yeasts, and particularly the two species mentioned above, may play a more significant role than previously recognised in the spoilage of poultry products.

\section{REFERENCES}

1. Deák, T., Beuchat, L. R. (1996) Handbook of Food Spoilage Yeasts. CRC Press, Boca Raton, FL., pp. 210.

2. Deák, T., Chen J., Beuchat, L. R. (2000) Molecular characterization of Yarrowia lipolytica and Candida zeylanoides isolated from poultry meat. Appl. Environ. Microbiol. (submitted)

3. Diriye, F. U., Scorzetti, G., Martini, A. (1993) Methods for the separation of yeast cells from the surfaces of processed frozen foods. Int. J. Food Microbiol. 19, 27-37.

4. Gallo, L., Schmitt, R. E., Schmidt-Lorenz, W. (1988) Microbial spoilage of refrigerated fresh broilers. Lebensm. Wiss. Technol. 21, 216-223.

5. Geornaras, L., Dykes, G. A., von Holy, A. (1994) Microbial populations associated with refrigerated poultry. S. Afr. J. Sci. 90, 570-582.

6. Ismail, S. A. S., Deák, T., Abd-Rahman H. A., Yassien, M. A. M., Beuchat, L. R. (2000) Presence and changes in populations of yeasts associated with raw and processed poultry products stored at refrigeration temperatures. J. Food Protect. (submitted)

7. Jackson, T. C., Acuff, G. R., Dickson, J. S. (1997) Meat, poultry and seafood. In: Doyle, M. P., Beuchat, L. R., Monville, T. J. (eds) Food Microbiology: Fundamentals and Frontiers. ASM Press, Washington, D. C., pp. 83-100.

8. Viljoen, B. C., Geornaras, L., Lamprecht, A., von Holy, A. (1998) Yeast population associated with processed poultry. Int. J. Food Microbiol. 15, 113-117. 